\title{
Laboratory evaluation of caricaceae plant as a locally sourced surfactant for gas hydrate inhibition in a laboratory mini flow loop
}

\author{
Virtue Urunwo Elechi ${ }^{1}$ [ - Sunday Sunday Ikiensikimama ${ }^{1}$. Joseph Atubokiki Ajienka ${ }^{1}$. \\ Onyewuchi Emmanuel Akaranta ${ }^{2} \cdot$ Okon Efiong Okon $^{1}$
}

Received: 3 March 2021 / Accepted: 19 May 2021 / Published online: 12 June 2021

(c) The Author(s) 2021

\begin{abstract}
The oil and gas business is serious business and involves millions of dollars so whatever mitigates flow assurance is taken seriously. One of such things is natural gas hydrates. Hydrates are crystalline solids formed when water under low temperatures and high pressures encapsulated natural gases $\left(\mathrm{C}_{1}-\mathrm{C}_{4}\right)$. They form blockages and impede the flow of gas which can lead to the loss of millions of dollars and at times lead to personnel death. Mitigation of gas hydrates has always been with chemicals especially for areas like deep offshore where accessibility is difficult. The chemicals that are in use currently are generally synthetic, expensive and hazardous to lives and environment hence the need for readily available locally sourced materials that are eco-friendly. This study considers and screens a locally sourced surfactant from the plant family caricaceae' Extract (CE) as a gas hydrate inhibitor in a locally fabricated 39.4-inch mini flow loop of $1 \frac{1}{2}$ inch internal diameter (ID) which mimics the offshore environment. Various pressure plots (pressure versus time, initial and final pressure versus time and change in pressure versus time) show that the CE performed better than MEG with percentage volumes of gas left in the system for 0.01-0.05 wt\% of the extract having values that ranged from 76.7 to 87.33, while volume left for MEG ranged between 70 and 74.67\% (1-5 wt\%). The CE performed better in small doses compared to those of MEG, in all weight percentages of study. Furthermore, the inhibition capacities which show the level of performance of the inhibitors was also used as a measure of inhibition for both inhibitors. The CE inhibited systems had values of $69.3,80.7,78.07,79.82$, and 83.3\%, while that of the MEG inhibited system was $60.53,55.26,73.68,72.81$, and $66.67 \%$ for the various weight percentages considered. The CE should be developed as gas hydrate inhibitors due to its effectiveness and eco-friendliness.
\end{abstract}

Keywords Gas hydrates · Eco-friendliness · Caricaceae extract (CE) • Monoethylene glycol (MEG) · Inhibition efficiency · Locally sourced surfactant

\section{Introduction}

With the decline in the potential of onshore oil and gas discoveries and exploration, there is the movement by oil and gas operators offshore. This has been embraced by many countries and governments. That is accepting drilling and production offshore. Historically, in the late 1940s, the first offshore production was recorded, and by the early $70 \mathrm{~s}$, about $20 \%$ of the oil supply was from offshore productions.

Virtue Urunwo Elechi

elechivirtue@yahoo.com

1 Department of Petroleum and Gas Engineering, University of Port Harcourt, Port Harcourt, Rivers State, Nigeria

2 ACE-PUTOR/Department of Chemistry, University of Port Harcourt, Port Harcourt, Rivers State, Nigeria
Though onshore reserves will in due course double, offshore reserves will increase by a factor of four (4) [9], due to the advancement in technology which has brought about offshore exploration and production.

The challenges encountered during offshore production are more demanding than those encountered during onshore production. The extreme water depths, pressures, and temperatures cause the flowlines and pipelines, and production risers to be under constant strain and this leads to solid hydrocarbon depositions in form of scales, asphaltenes, waxes, and hydrates. According to [16], hydrocarbon solids can be deposited anywhere and blocked the production system. This causes constriction in the internal diameter of the systems as well as obstruction of flow hence a reduction in production. 
Huge financial losses, as well as safety and environmental concerns as a result of pipeline obstructions from gas hydrates due to blockages and cessation of flow, are possible [25]. Hydrates can form when carbon dioxide is used for enhanced oil recovery according to [13]. During drilling, when a kick occurs and gas enters into the formation, subsea transfer pipelines, pipelines, chokes, Blow Out Preventers (BoPs), and risers can be plugged [28]. Even though the thermodynamic conditions for formation of gas hydrate are crossed, it does not automatically mean that hydrate plugs will be formed [16]. This is to say that even if they form, as long as they do not deposit and agglomerate, they cannot cause blockages to the pipelines and other systems.

The solid deposition causes strain on the production facility such as stenosis, increased roughness of pipe causing an increase in pump pressure, interference with valve operations, operational and safety problems (due to solid build-up in process vessels and storage tanks), reduced productivity due to clogging of perforations and sand face, plugged surface flow lines and tubing, wear and tear of equipment during mechanical handling, as well as production downtime. These lead to damages to equipment and ultimately shut down. There is, therefore, a need to prevent hydrate formation.

Gas hydrates form when water encloses gases and form cavities under high pressures (>2900 psig) and low temperatures $\left(32^{\circ} \mathrm{F}\right.$ or $\left.0{ }^{\circ} \mathrm{C}\right)$. An adequate amount of water is vital for the formation of gas hydrates. This is because its molecules are arranged in regular orientations as a result of its hydrogen bond (covalent bonding between two hydrogen and one oxygen atom gives it a peculiar property and causes it to form a hexagonal pattern, with hydrogen having positive changes, while oxygen has a negative charge). These molecules that are so aligned are made stable by hydrate formers or gas molecules in the cages formed by water molecules via weak Van der Waals forces. That is to say, guest molecules and host molecules do not bond chemically [27]. When all the cages are formed by the water molecules (host), they are made of $85 \%$ water and $15 \%$ gases [26]. Very small guest molecules such as hydrogen and helium with diameters less than $3.8 \AA$ and large molecules such as pentane, hexane, and larger paraffin hydrocarbon with a diameter larger than $7 \AA$ do not form gas hydrates. For hydrates to form, the hydrate former must not be more soluble than sulfur $\left(\mathrm{SO}_{2}\right)$ dioxide (which is highly soluble in water, extremely temperature dependent and is about 400 times more soluble at $0{ }^{\circ} \mathrm{C}$ than at $\left.90{ }^{\circ} \mathrm{C}[15]\right)$ and must not interfere with hydrogen bonding [3], and the hydrate formers are supposed to be housed inside the water cages and move freely inside without interacting with the water molecules [27] which are bonded together via hydrogen bonding. Other factors such as nucleation sites (scale, dirt, welded spot, valves, elbows, tees and roughness of pipelines) and turbulence (agitations during fluid flow and regions of high velocity) favor gas hydrate formation [3]. According to [21], they are ice-like in appearance and brittle and are formed when light ends of hydrocarbons such as methane, ethane, propane, and butane come in contact with water. Other gases such as nitrogen, carbon dioxide, and hydrogen sulfide can also form gas hydrates.

There are four techniques to prevent hydrate formation:

(1) Removal of free and dissolved water from the system with separators, glycol dehydration, molecular sieves, or other methods

(2) Maintain high temperatures so that hydrates do not form

(3) Maintain low pressures to keep all phases fluid

(4) Inject an inhibitor to prevent hydrate formation.

With technological development and the state-of-the-art methods of preventing gas hydrates, there are technology for hydrate plug prevention. Three new types of hydrate inhibitors (dispersants/anti-agglomerants, kinetic inhibitors, and emulsifiers) called low-dosage hydrate inhibitors exist asides methanol (MeOH) and monoethylene glycol (MEG) (which are known as thermodynamic hydrate inhibitors). They were field tested in the $90 \mathrm{~s}$. Although the concentrations of the inhibitors are low, chemical solutions are very expensive (as flow assurance remedies) for long tie-backs between wellheads and platforms. Other technologies for hydrate prevention are slurry flow and heating/insulation.

According to [11], after laboratory studies showed a subcooling of $45^{\circ} \mathrm{F}$, the commercial use of dispersants/ anti-agglomerants began in the Gulf of Mexico. They are particularly effective in hydrate plug prevention for shut-ins and restarts, although it requires more extensive field testing. These chemicals work by converting water into finely dispersed hydrate particles to be transported in hydrocarbon liquid. They are quaternary ammonium salts that are long chained which have about three or four branches that can easily form gas hydrates, but the fourth branch projects from the structure and prevents the agglomeration to larger plugs. They require hydrocarbon liquids to perform that is to say there has to be a substantial amount of hydrocarbon liquid (maximum volume of water of $40 \%$ of total liquid phase) to disperse the hydrates. The more the inhibitors are used commercially, the environmental concerns abound and have to be tackled (especially water purity).

Kinetic inhibitors are polymers containing pendant groups and carbon backbone. They act by adsorbing into hydrate cages (that are partially formed), such that the polymers are aligned along the surface of the hydrate crystal. This forces the hydrate crystals to grow around the polymers causing the hydrates to be stabilized as small particles in aqueous phase. Liquid hydrocarbon does not necessarily have to be 
present for this to happen. They have been found out to be effective at subcooling of $20^{\circ} \mathrm{F}$ in doses of $550-3000 \mathrm{ppm}$ [12], but they can still fail during shut-in and restart causing gas hydrate formation.

The dispersant/anti-agglomerants and the kinetic inhibitors constitute the low-dosage hydrate inhibitors (LDHIs). A major setback with the use of LDHIs is that the unprocessed effluent has to be produced inside the hydrate's zone of stability [24]. Other chemical types called emulsifiers help to ensure that the water in oil phases is stabilized, so that they do not break out to form hydrates. Fadnes [10] has it that natural emulsifiers are contained in some oil, such that even when hydrate formation conditions which will convert water to hydrates are favored, the water remains stabilized in the oil phase. There has been a lot of effort to identify, extract, and reinject these natural emulsifiers (stabilizing agent) into oils that do not have them, but this has not been successful. The use of artificial emulsifiers has proved effective in gas hydrate mitigation [22]. The problem with their usage is that of cost of emulsion breakage and the cost of adapting them to suit each oil application.

Slurry flow does not allow the hydrates formed in the fluid phase to stick to the wall of the pipe. It uses the concept developed by [1]. Subsea separators are used to remove majority of the water produced and subsequent exchange of heat to temperatures of the sea floor (hydrate forming area) for a perfect slurry system. Fluids coming from the reservoir do so with high temperatures and so there is the need to preserve this high temperature or to add heat to the line so as to keep the system from entering the hydrate formation zone. This is done via coating (pipelines), pipe-in-pipe (PIP) binding (which is a concern when leakages occur and needs fixing), and use of vacuum insulated pipes (or pipes with insulating gases), but it is very expensive; hence, its commercial usage is not applicable.

A study on the effect of kinetic hydrate inhibitors on methane hydrate growth in gas-liquid separation phase was carried out by [4]. They opined that the initial position of kinetic hydrate inhibitor (KHI) had significant effect on methane hydrate growth, and that under gas-liquid separation, the two KHIs PVP and PVP-A had good inhibitory effect on gas hydrate growth. The delay of methane hydrate nucleus growth had to do with the adsorption of the molecules of the inhibitors on the hydrae nucleus surface reducing their direct contact with the surrounding water and methane molecules. In a study carried out by [14], it was found that polyurethanes had excellent adhesion properties, which were environmentally friendly, non-toxic, and non-pollutant to air and produced water. They are hydrophobic and insoluble in water and as such needed modification by incorporating ionic/or non-ionic groups in their polymer structures (this was necessitated as a result of rise in solvent cost, environmental concerns, and the ease of cleaning reactor systems, so water was used as main solvent in polyurethanes application) in order for them to be dispersed in water. The study aimed at helping to understand the importance and characteristics of polyurethanes.

These methods especially the use of chemicals (dispersants, emulsifiers, methanol, and monoethylene glycol) has been in place with varying degrees of disadvantages. The need for the use of chemicals that are more advantageous to human lives and the environment is key. This necessitated research in the use of naturally occurring plant extracts (which are water soluble and need no modification) to solve the problem of gas hydrate formation [5-7]. This work considers the use of such extract from Caricaceae family to inhibit gas hydrate with the aim of reducing environmental foot prints caused by synthetic chemicals.

\section{Experimental Set up}

This work is a laboratory investigation of the effect of a local an commercial inhibitor on gas hydrate formation. Experiments were run using a locally designed and fabricated laboratory Mini Flow Loop (Institute of Petroleum Studies Flow loop). For details of its specification and operation including how the experiments were carried out refer to $[19,5-7]$. For the materials and methods as well as plant description, refer to [8]

\section{Results and discussion}

\section{Suppression performance plots}

The performance of the Caricaceae extract (CE) is screened using the laboratory flow loop which typically tells the pressure and temperature variation with time as the experiment goes on. Each of the weight percentages of the Caricaceae extract (CE) was screened on the laboratory flow loop to see the effect of the various weight percentages on hydrate mitigation.

\section{a) Pressure versus Time plots}

The pressure versus time plots for the various weight percentages of the locally sourced surfactant, caricaceae extract (CE) are shown in Fig. 1. This plot is an indication of how well the various weight percentages regulated the pressures in the systems as compared to that of the uninhibited experiment. For $0.01 \mathrm{wt} \% \mathrm{CE}$, the decrease in pressure was from 150 to 115 psi in $120 \mathrm{~min}$. $0.02 \mathrm{wt} \%$ had values of $150-128$ psi for the same time frame; $0.03 \mathrm{wt} \%$ had values of $150-125$ psi. For $0.04 \mathrm{wt} \%$, the pressure values were $150-127$ psi, while $0.05 \mathrm{wt} \%$ values were $150-131$ at the 


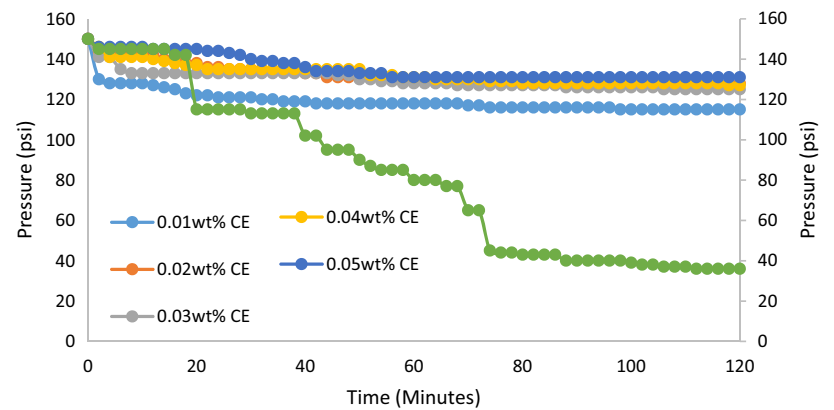

Fig. 1 Pressure versus time for $0.01-0.05$ wt\% caricaceae extract CE and uninhibited experiment

end of $120 \mathrm{~min}$. The pressure was more regulated using 0.02 wt $\%$ CE. A pressure of 128 psi was observed at the end of the experiment which was an indication that the usage of gas to form gas hydrates was lesser than in other weight percentages (except for $0.05 \mathrm{wt} \%$ ). At this weight percentage, the local inhibitor's profound influence on hydrate growth was brought to bear. The strong attraction between hydrophobic group and the gas molecules inhibited the mass transfer of gas molecules from the gas phase to the aqueous phase decreasing the growth rate [4]. Howbeit, the various weight percentages of the local inhibitor were all able to regulate the pressure drop in the system as opposed to the uninhibited experiment with a value of $36 \mathrm{psi}$ at the end of $120 \mathrm{~min}$. This could be attributed to the fact that the gas was encapsulated by water to form clathrate, thereby leading to an increase in hydrate content and decrease in total potential energy which is indicative of a sustained hydrate growth [20]. This weight percentage of 0.02 is key as it helps as a guide in hydrate inhibition in terms of volume (concentration) of inhibitor to be used above which it is no longer economical.

Figure 2 shows the Temperature versus Time plot for 0.01-0.05wt CE and uninhibited experiment. For 0.01-0.05 $\mathrm{wt} \%$, the temperature decreased from $30^{\circ} \mathrm{C}$ to 6.5 (for 0.01 and $0.02 \mathrm{wt} \%), 7.5,7$ (0.03 and $0.04 \mathrm{wt} \%$ ), and from $32{ }^{\circ} \mathrm{C}$

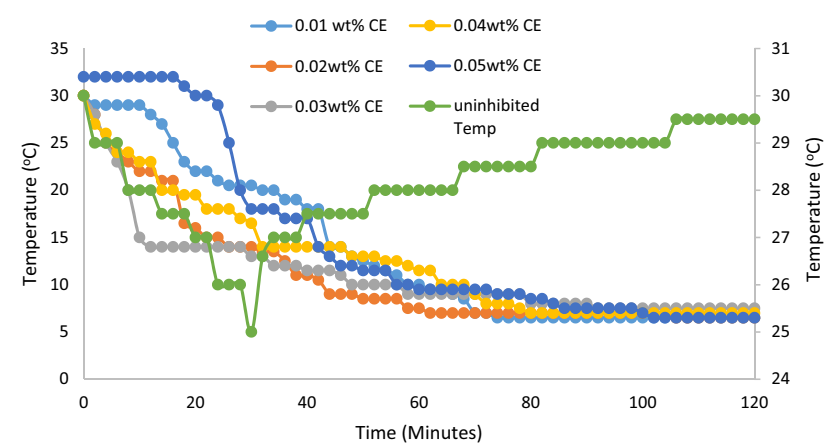

Fig. 2 Temperature versus time for $0.01-0.05 \mathrm{wt} \%$ caricaceae extract $\mathrm{CE}$ and uninhibited experiment to $6.5{ }^{\circ} \mathrm{C}(0.05 \mathrm{wt} \%)$ at the end of $120 \mathrm{~min}$. All the weight percentages regulated the temperatures in the system better than in the uninhibited where the temperature declined steadily from $30^{\circ} \mathrm{C}$ to 27 in $20 \mathrm{~min}$ and then $25^{\circ} \mathrm{C}$ in $30 \mathrm{~min}$ after which it increased to $29.5^{\circ} \mathrm{C}$ in $120 \mathrm{~min}$. The increase in temperature resulted in the dissolution of methane gas in the cooling water which caused a reduction in induction time (inducing the agglomeration and precipitation of crystal particles as saturation was reached signaling the onset of crystallization which is seen as a spike in temperature. This was due to the enthalpy of fusion occasioned by the release of latent heat, so that heat was given out as the experiment progressed. This is in line with the findings of $[2,20,30]$

\section{Suppression performance comparison of caricaceae extract $\mathrm{CE}$, and monoethylene glycol (MEG)}

\section{(1) Pressure versus Time plots}

Figures 3, 4, 5, 6, and 7 show the pressure versus time for 0.01-0.05/1-5 wt\% CE and MEG. As a way of comparison, the pressure versus time plot indicates how well the

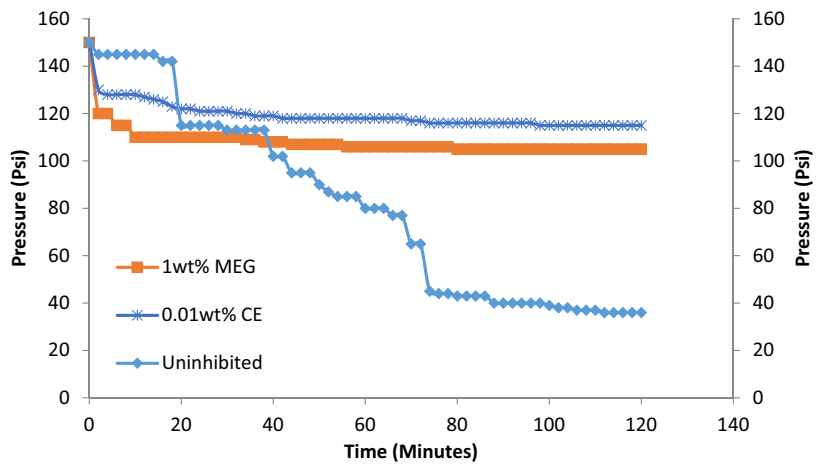

Fig. 3 Pressure versus Time for $0.01 \mathrm{wt} \%$ caricaceae extract CE, 1 wt $\%$, monoethylene glycol (MEG), and uninhibited experiment

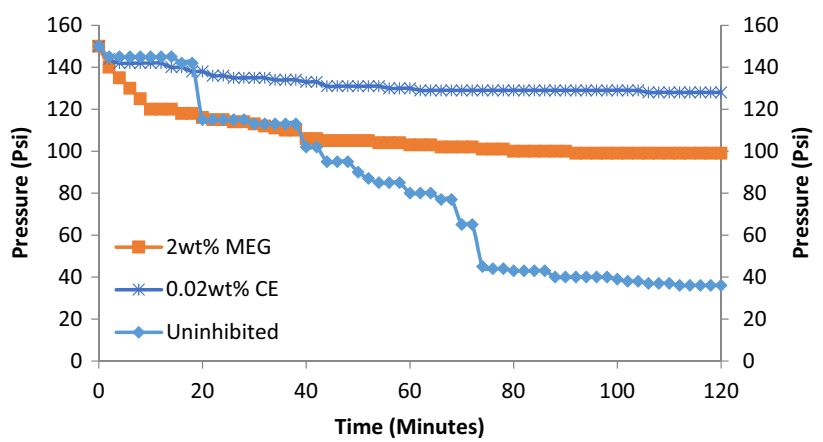

Fig. 4 Pressure versus time for 0.02 wt $\%$ caricaceae extract CE, 2 $\mathrm{wt} \%$, monoethylene glycol (MEG), and uninhibited experiment 


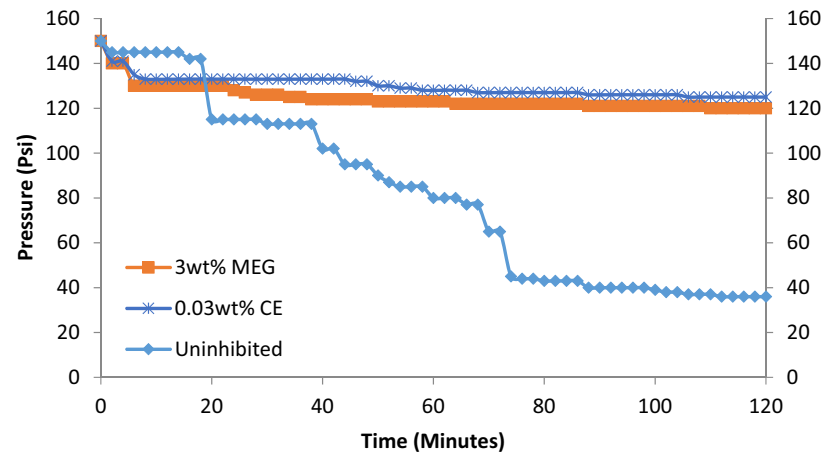

Fig. 5 Pressure versus time for 0.03 wt $\%$ caricaceae extract CE, 3 $\mathrm{wt} \%$, monoethylene glycol (MEG), and uninhibited experiment

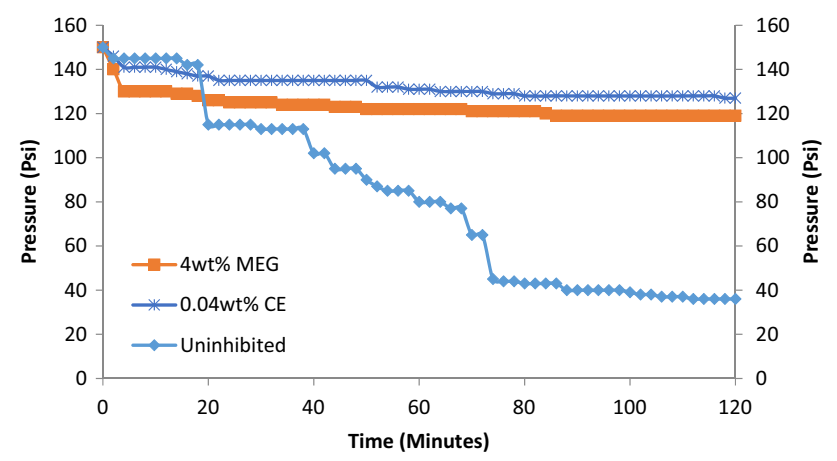

Fig. 6 Pressure versus time for $0.04 \mathrm{wt} \%$ caricaceae extract CE, 4 $\mathrm{wt} \%$, monoethylene glycol (MEG), and uninhibited experiment

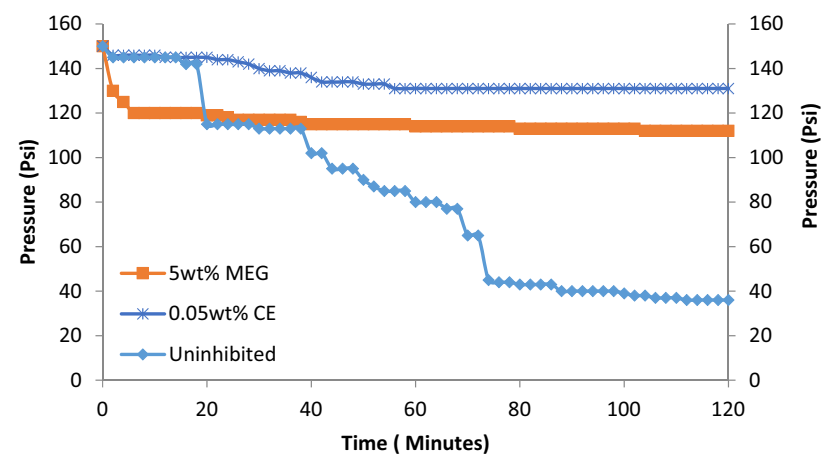

Fig. 7 Pressure versus time for $0.05 \mathrm{wt} \%$ caricaceae extract CE, 5 $\mathrm{wt} \%$ mono ethylene glycol (MEG), and uninhibited experiment

pressures of the system are regulated. A well-regulated system has higher pressure values with time as the experiment progresses. For $0.01-0.05 \mathrm{wt} \% \mathrm{CE}$, pressure decreased from 150 psi to $115,128,125,127$, and $131 \mathrm{psi}$ at the end of $120 \mathrm{~min}$, while pressure values for 1-5 wt\% MEG for same time interval were $105,99,120,119$, and $12 \mathrm{psi}$, respectively.
The caricaceae extract, CE inhibited system had more regulated pressures than the MEG inhibited system in all the weight percentages considered therefore performed better. The mini flow loop used has pressure increase or decrease as an indication of hydrate formation or inhibition. A rapid pressure decrease from the base pressure during the time frame of the experiment is an indication of gas hydrate formation. When this happens, the water molecules encapsulate the gas in the system which contains the hydrate formers to forms cages. During inhibition, the inhibitors align in such a way that the water forms around them instead of forming cages. Both systems had more pressure regulation unlike in the uninhibited scenario where there was a rapid pressure decrease from 150 to 36 psi. Gas mixed rapidly with water leading to fast agglomeration and growth in hydrate crystals which is considered the first phase of gas hydrate formation [18].

The caricaceae extract CE contains bioactive compounds such as saponins, tannins, alkaloids, and flavonoids (this is the predominant constituent and is exemplified by Quercetin and catechin). They have 5 hydroxyl, $\mathrm{OH}$ group in them, while MEG has just 2 hydroxyl group in them. The presence of more hydroxyl groups in the extract allows for direct and faster interaction with water, thereby disrupting its ability to form crystals. MEG has inter-hydrogen bonding between its molecules which affects its interaction with water. The performance of CE may be attributed to the fact that it was used in its pristine state, unlike MEG which has been synthesized. Since MEG is a viscous fluid, this may have contributed in it not performing well unlike the $\mathrm{CE}$. The growth of hydrate in the system with local inhibitor, CE was significantly slower than that of the MEG inhibited system as seen from the pressure profiles at the end of the experiment.

\section{(2) Change in pressure $(\Delta \mathrm{P})$ versus Time plots}

The change in pressure is an indication of how much pressure was used up in the system. The lesser the pressure change, the better the efficacy of the inhibitor used. Figures $8,9,10,11,12$ show the change in pressure versus time for $0.01 / 1-0.05 / 5 \mathrm{wt} \%$ of CE and MEG. $0.01-0.05 \mathrm{wt} \%$ caricaceae extract $C E$ had change in pressure values of 35,22 , 25,23 , and $19 \mathrm{psi}$, respectively, at the end of $120 \mathrm{~min}$, while $1-5 \mathrm{wt} \%$ of $45,51,30,31$, and $38 \mathrm{psi}$ at the end of $120 \mathrm{~min}$.

The caricaceae extract CE had the least change in pressure values in all the weight percentages and performed better than all the weight percentages of MEG, even though it was used in lesser weight percentages when compared to MEG. The local inhibitor was able to prevent hydrate by adsorption to the hydrate crystal surface due to the presence of the functional group contained in them. This is also as a result of less interaction between molecules of the gas and the water due to incomplete formation of cages, as sterical

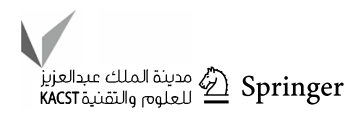




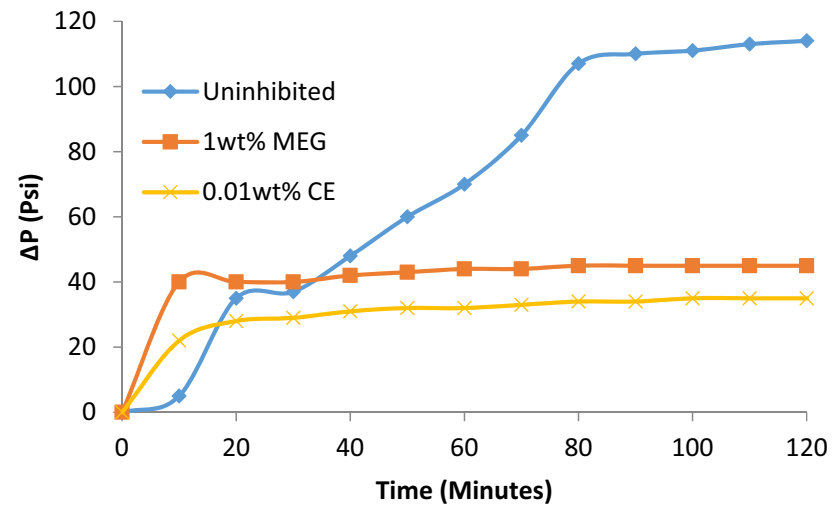

Fig. $8 \Delta \mathrm{P}$ versus time for $0.01 \mathrm{wt} \%$ caricaceae extract $\mathrm{CE}, 1 \mathrm{wt} \%$ monoethylene glycol (MEG), and uninhibited experiment

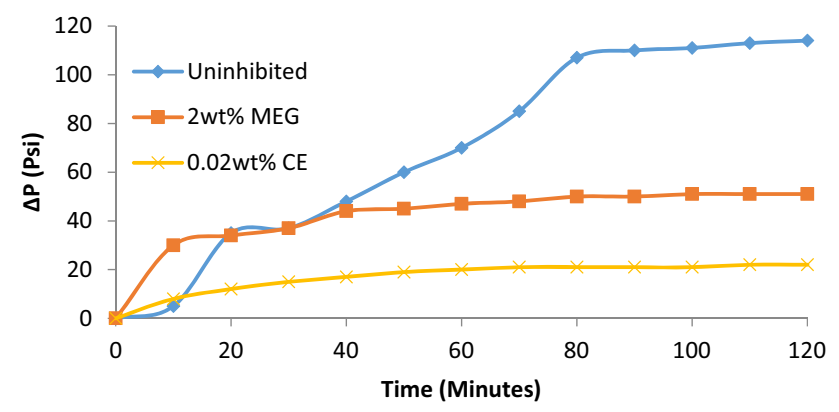

Fig. $9 \Delta \mathrm{P}$ versus time for $0.02 \mathrm{wt} \%$ caricaceae extract CE, $2 \mathrm{wt} \%$ monoethylene glycol (MEG), and uninhibited experiment

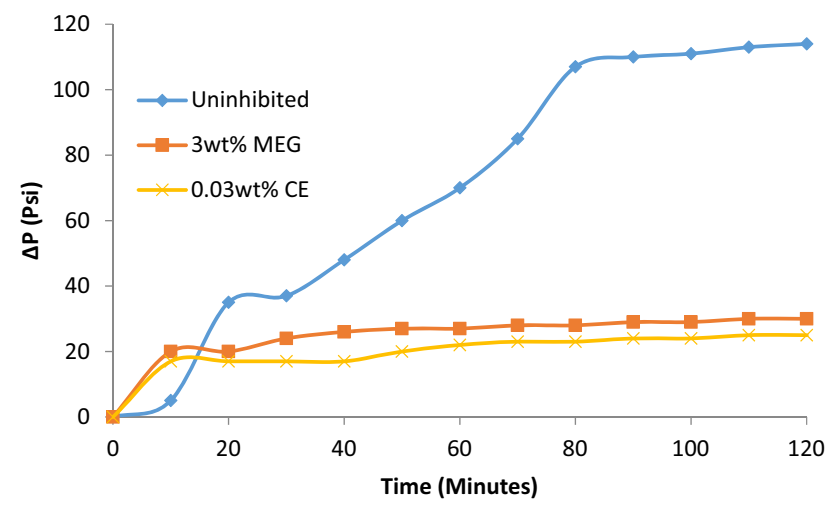

Fig. $10 \Delta \mathrm{P}$ versus time for $0.03 \mathrm{wt} \%$ caricaceae extract $\mathrm{CE}, 3 \mathrm{wt} \%$ monoethylene glycol (MEG), and uninhibited experiment

blocking occurred [4], so the local inhibitor CE was able to reduce the surface tension and form a strong hydrogen bonds with water molecules. The presence of the hydroxyl groups alongside amide groups also added to its inhibitory ability. This agrees with the fact that the effect of KHIs is mainly due to the hydrogen bond between amide group and water molecules on the hydrate surface [17], [23]. ***

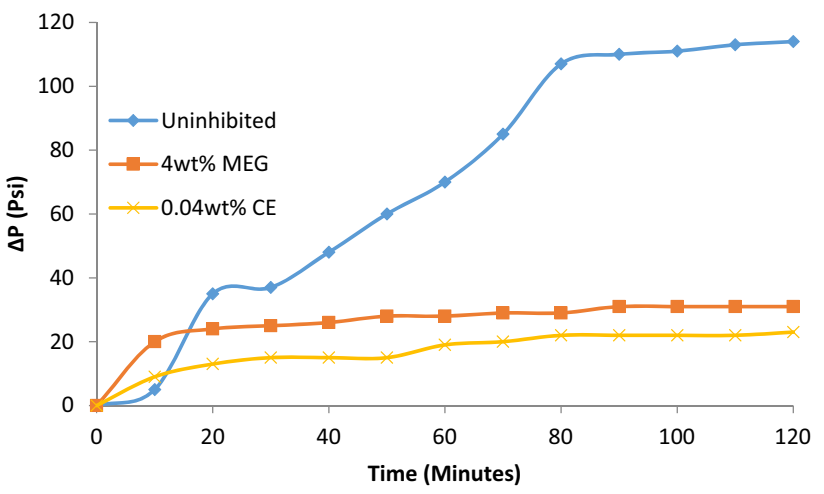

Fig. $11 \Delta \mathrm{P}$ versus time for $0.04 \mathrm{wt} \%$ caricaceae extract CE, $4 \mathrm{wt} \%$ monoethylene glycol (MEG), and Uninhibited Experiment

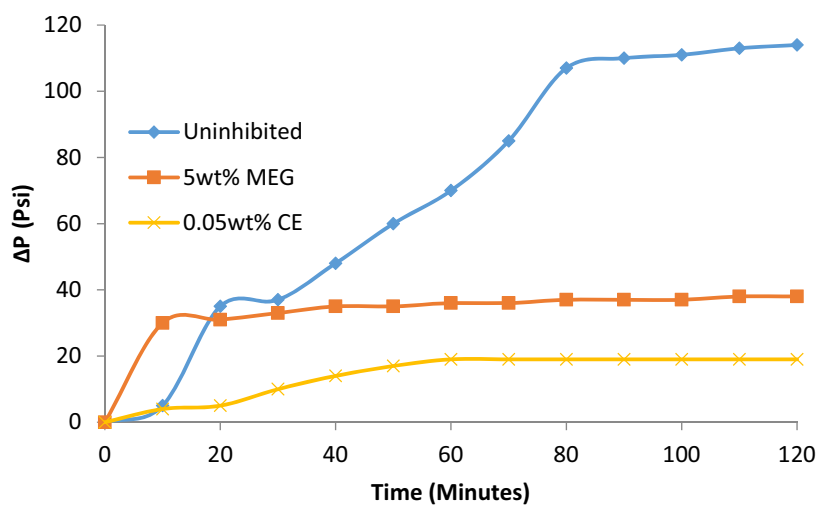

Fig. $12 \Delta \mathrm{P}$ versus time for $0.05 \mathrm{wt} \%$ caricaceae extract CE, $5 \mathrm{wt} \%$ mono ethylene glycol (MEG), and uninhibited experiment

The uninhibited experiment had a change in pressure value of 114 psi which was greater than $0.01-0.05 \mathrm{wt} \%$ CE's overall change in pressure value by $95 \mathrm{psi}$ and greater than $1-5 \mathrm{wt} \%$ MEG overall pressure value by $76 \mathrm{psi}$. This indicated that the system was almost devoid of gas at the end of $120 \mathrm{~min}$ due to the encapsulation of gases by water and were well aligned around the gas molecules to form cages which trapped the gas molecules for the formation of gas hydrates [27]

\section{(3) Initial $\left(\boldsymbol{P}_{i}\right)$ and Final Pressure $\left(P_{f}\right)$ plots}

The quantity of gas left in the systems is indicative of the final pressure values and denotes how the inhibitors suppressed gas hydrate formation as well as their effectiveness. Figures 13, 14, 15, 16, 17 show the initial and final pressures versus time for $0.01-0.05 \mathrm{wt} \% \mathrm{CE}$ and $1-5 \mathrm{wt} \%$ MEG. At the end of $120 \mathrm{~min}$, the volume of gas left as a measure of final pressure was 76.7, 85.33, 83.33, 84.67 and $87.33 \%$ while the values for MEG were $70,66,80,79.33$ and $74.67 \%$, respectively for $1-5 \mathrm{wt} \%$. Again, in all the weight percentages considered, the CE had a larger percentage of 


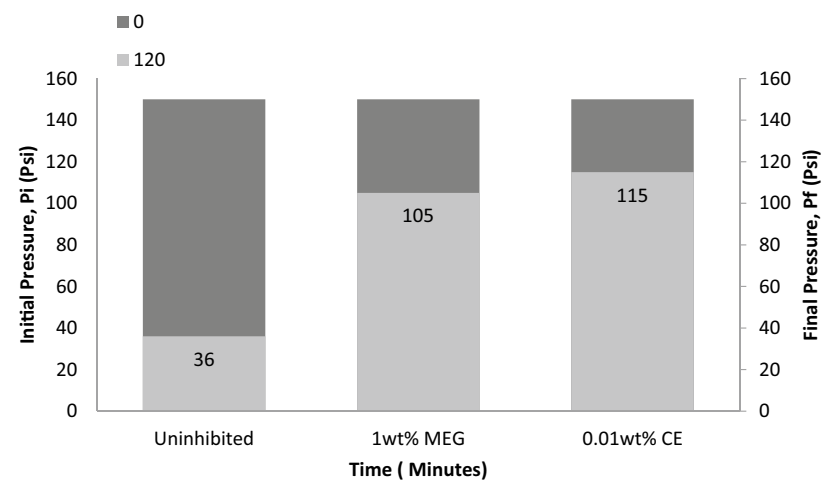

Fig. $13 \mathrm{Pi}$ and $\mathrm{Pf}$ versus time for $0.01 \mathrm{wt} \%$ caricaceae extract $\mathrm{CE}, 1$ $\mathrm{wt} \%$ mono ethylene glycol (MEG), and uninhibited experiment

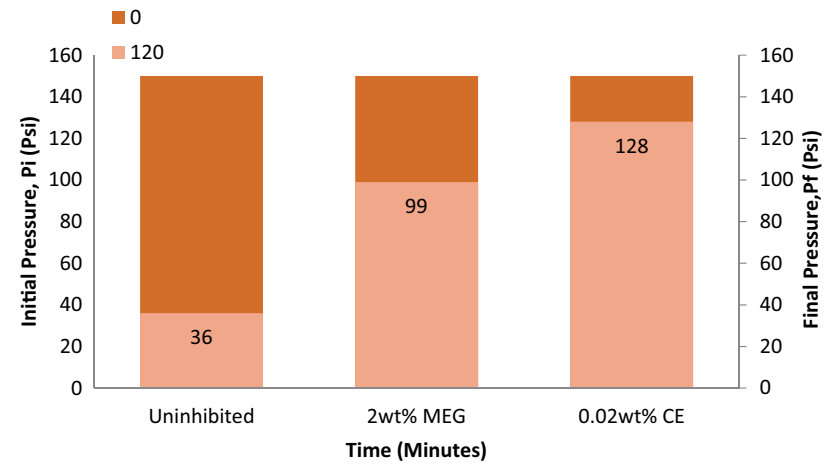

Fig. $14 \mathrm{Pi}$ and $\mathrm{Pf}$ versus time for $0.02 \mathrm{wt} \%$ caricaceae extract $\mathrm{CE}, 2$ $\mathrm{wt} \%$ monoethylene glycol (MEG), and uninhibited experiment

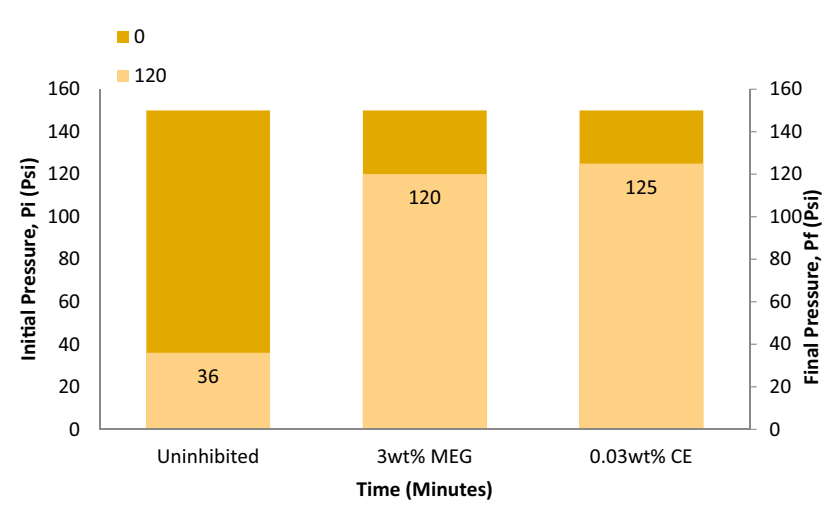

Fig. $15 \mathrm{Pi}$ and $\mathrm{Pf}$ versus time for $0.03 \mathrm{wt} \%$ caricaceae extract CE, 3 $\mathrm{wt} \%$ mono ethylene glycol (MEG), and uninhibited experiment

pressure retained in the system which showed its efficacy when compared to MEG. $0.02 \mathrm{wt} \% \mathrm{CE}$ had a better performance than $2 \mathrm{wt} \%$ MEG as well as other weight percentages. This can be attributed to the fact that at this weight percentage, the molecules did not just adsorb to the water/

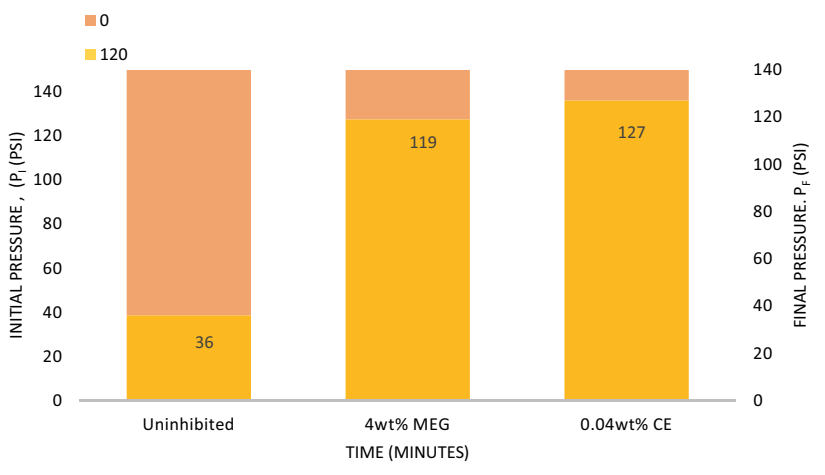

Fig. $16 \mathrm{Pi}$ and Pf versus time for $0.04 \mathrm{wt} \%$ caricaceae extract CE, 4 wt\% monoethylene glycol (MEG), and uninhibited experiment

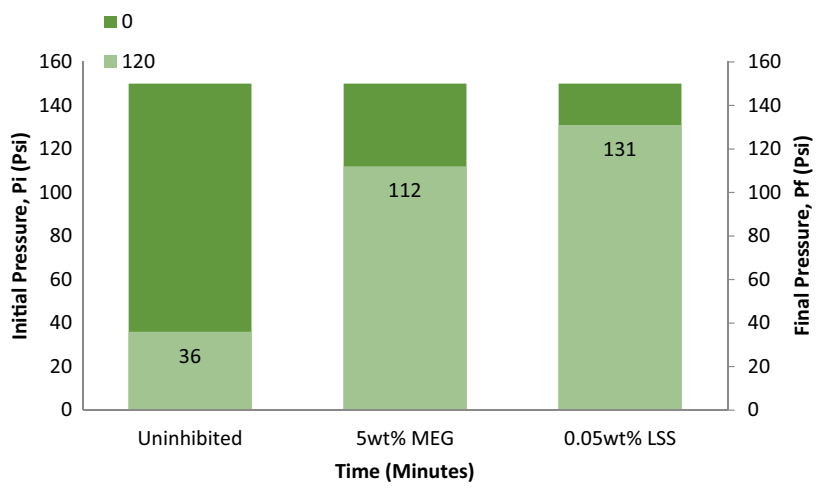

Fig. $17 \mathrm{Pi}$ and Pf versus Time for $0.05 \mathrm{wt} \%$ caricaceae extract CE, 5 wt\% monoethylene glycol (MEG), and uninhibited experiment

gas surface, but were more hydrophilic and more effective in suppressing the growth of hydrate crystal [20]. For the uninhibited experiment, at the end of the experiment, the percentage was $24 \%$. This showed the rapid use up of the gas in the system to form gas hydrate. As gas molecules dissolve continuously in the liquid phase and migrates toward the hydrate crystal nucleation zone to form new cages, there will be a continuous decrease in the number of gas molecules in the gas phase, and therefore, the dissolution rate of gas in water is reflected by the volume of gas left in the gas phase at the end of the experiment which aligns with [4]

\section{(4) Inhibition Efficiency}

The inhibition efficiency (IE) versus the weight percentage of inhibitors is shown in Fig. 18 and is a measure of the rate at which the various inhibitors performed, and further ascertains the efficacy of the inhibitors. The efficiency of caricaceae extract CE at $0.02 \mathrm{wt} \%$ was outstanding, because it was greater than the other weight percentages by $11.4 \%$, $2.63,0.88 \%$ and less than $0.05 \mathrm{wt} \%$ by $2.63 \%$ (mitigating 


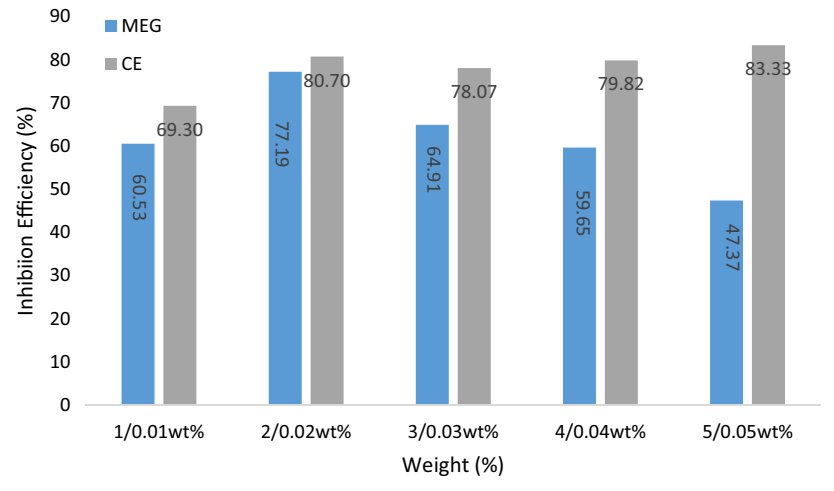

Fig. 18 Inhibition efficiency versus weight $\%$ for $0.01-0.05$ wt $\%$ caricaceae extract CE and 1-5 wt\%, monoethylene glycol (MEG)

at $0.05 \mathrm{wt} \%$ is not necessary, since the difference is not so significant, and hence, $0.02 \mathrm{wt} \%$ is taken as the optimum). The decreases in 0.03 and $0.04 \mathrm{wt} \%$ could also be attributed to reduction in their ability to inhibit. The insignificant inhibition efficiency at $0.05 \mathrm{wt} \%$ of the caricaceae extract is in line with a study carried out on ionic liquid where concentrations greater than $1 \mathrm{wt} \%$ did not offer a lot of advantage [29]. The performance at $0.02 \mathrm{wt} \%$ could be that at this weight percentage, the inhibitor molecules were more aligned and probably had complete adsorption on the surface of hydrate crystal, reducing the hydrate cluster/nucleus contact with water and gas molecules, to prevent growth and stabilization of the cages in all except $0.05 \mathrm{wt} \%$ [4]. The inhibition efficiency of the local inhibitor was greater than that of MEG in all the weight percentages considered even in lower dosages as against the higher dosages for MEG whose inhibitory performance could have been affected by its viscous nature.

\section{Conclusions}

This study has shown the effectiveness of a locally sourced surfactant caricaceae extract (CE) and its efficiency over the conventional monoethylene glycol (MEG). The various pressure plots (pressure versus time, initial and final pressure versus time, and change in pressure versus time) showed that the caricaceae Extract CE performed better than MEG with percentage volumes of gas left in the system for $0.01-0.05 \mathrm{w} \%$ of the extract having values that ranged from 76.7 to 87.33 , while volume left for MEG ranged between 70 and $74.67 \%$ (1-5 wt \%). The CE was used in small doses as compared to those of MEG. The CE performed better in all weight percentages considered.

The optimum weight percentage for inhibition for the caricaceae extract (CE) inhibited system is $0.02 \mathrm{wt} \%$. This is because at this weight percentage, the \% volume of gas left in the system at the end of the experiment was high $(85.33 \%)$. The performance at this weight percentage was attributed to the fact that at this weight percentage, the inhibitor's molecules were more aligned and probably had complete adsorption on the surface of hydrate crystal, reducing the hydrate cluster/nucleus contact with water and gas molecules, to prevent growth and stabilization of the cages in all weight percentages except $0.05 \mathrm{wt} \%$. The decreases in 0.03 and $0.04 \mathrm{wt} \%$ could also be attributed to reduction in their ability to inhibit. Even though $0.05 \mathrm{wt} \%$ had a higher volume of $87.33 \%$, this value is just $2 \%$ above that at $0.02 \mathrm{wt} \%$; therefore, it will be needless and non-economical to inhibit above $0.02 \mathrm{wt} \%$. The insignificant inhibition efficiency at $0.05 \mathrm{wt} \%$ of the caricaceae extract is in line with a study carried out on ionic liquid where concentrations greater than $1 \mathrm{wt} \%$ did not offer a lot of advantage. The effectiveness of the caricaceae extract CE over MEG also comes to bear here, because MEG was used in higher weight percentages compared to the CE yet the optimum weight percentage for MEG was $3 \mathrm{wt} \%$ with a percentage volume of gas at the end of $80 \%$ which is $5.33 \%$ less than that of caricaceae extract $\mathrm{CE}$ at an optimum weight percentage of $0.02 \mathrm{wt} \%$. The caricaceae extract CE is locally and readily available asides being eco-friendly and have proven to be more effective than MEG in all weight percentages considered, and therefore, it should be harnessed as gas hydrate inhibitors instead of the synthetic hydrate inhibitor MEG.

Acknowledgements The authors are grateful to ACE-CEFOR University of Port Harcourt and the Institute of Petroleum Studies Laboratory for their support in carrying out this research.

Open Access This article is licensed under a Creative Commons Attribution 4.0 International License, which permits use, sharing, adaptation, distribution and reproduction in any medium or format, as long as you give appropriate credit to the original author(s) and the source, provide a link to the Creative Commons licence, and indicate if changes were made. The images or other third party material in this article are included in the article's Creative Commons licence, unless indicated otherwise in a credit line to the material. If material is not included in the article's Creative Commons licence and your intended use is not permitted by statutory regulation or exceeds the permitted use, you will need to obtain permission directly from the copyright holder. To view a copy of this licence, visit http://creativecommons.org/licenses/by/4.0/.

\section{References}

1. Austvik T (1992) Hydrate Formation and Behavior in Pipes. Ph.D. Dissertation, Norwegian University of Science and Technology, Trondheim, Norway

2. Bishnoi PR, Natarajan V (1996) Formation and decomposition of gas hydrates. Fluid Phase Equilib 117:168-177

3. Carrol J (2009) Natural gas hydrates: a guide for engineers, 2nd edn. Springer, Berlin, pp 1-48 
4. Cheng L, Wang L, Li Z, Liu B, Chen G (2019) Inhibition effect of kinetic hydrate inhibitors on the growth of methane hydrate in gas-liquid phase separation. Energies 12:4482. https://doi.org/10. 3390/en/2234482

5. Elechi VU, Ikiensikimama SS, Ajienka JA, Akaranta O, Onyekonwu MO, Odutola TO, Okon OE (2018) Gas hydrate inhibition in a simulated offshore environment using local inhibitor. In: SPE Paper 193439 presented at Nigeria Annual International Conference and Exhibition, held in Lagos Nigeria

6. Elechi VU, Ikiensikimama SS, Ajienka JA, Akaranta O, Onyekonwu MO, Okon OE (2019) Comparative analysis of gas hydrate inhibitors: local and conventional. In: SPE 197429 presented at the Abu Dhabi International Petroleum Exhibition and Conference held in Abu Dhabi, UAE, pp 11-14

7. Elechi VU, Ikiensikimama SS, Ajienka JA, Akaranta O, Onyekonwu MO, Okon OE (2020) The use of a bench-scale high-pressure apparatus to evaluate the effectiveness of a locally sourced material as gas hydrate. Sci Afr. https://doi.org/10.1016/j.sciaf. 2020.e00300

8. Elechi VU, Ikiensikimama SS, Ajienka JA, Akaranta O, Onyekonwu MO, Okon OE (2021) Mitigation capacity of an ecofriendly locally sourced surfactant for gas hydrate inhibition in an offshore environment. J Pet Explor Prod 11(4):1797-1808. https:// doi.org/10.1007/s 13202-021-01127-z (ISSN 2190-0558)

9. ETA Offshore Seminars (1976) The technology of offshore drilling completion and production. Penn Well Publishing Company, Tulsa

10. Fadnes FH (1996) Natural hydrate inhibiting components in crude oils. Fluid Phase Equilib 117:186

11. Frostman LM, Przybylinski JL (2001) Successful applications of anti-agglomerant hydrate inhibitors. SPE Int Sympos Oilfield Chem. https://doi.org/10.2118/65007-MS

12. Fu SB, Cenegy LM, Neff CS (2001) A summary of successful field applications of a kinetic hydrate inhibitor. SPE Int Sympos Oilfield Chem. https://doi.org/10.2118/65022-MS

13. Gbaruko BC, Igwe JC, Gbaruko PN, Nwokeoma RC (2005) Gas hydrates and clathrates: flow assurance, environmental and economic perspectives and the Nigerian Liquefied Natural Gas Project. J Pet Sci Eng 56:192-198

14. Honarkar H (2017) Waterborne polyurethanes: a review. J Dispers Sci Technol. https://doi.org/10.1080/01932691.2017.1327818

15. IARC Monograph (1992) IARC Working Group on the evaluation of carcinogenous risks to humans: occupational exposures to mist and vapors from strong inorganic acids and other industrial chemicals. (Lyon (FR): International Agency for Research on Cancer. https://www.ncbi.nlm.nib.gov/books/N3k424646/. Accessed 25 Feb 2021

16. Joshi N (2001) A systematic approach in deep water flow assurance fluid characterization. SPE Paper 71546 Presented at SPE Annual Technical Conference and Exhibition, New Orleans, Louisiana, USA.

17. Kelland MA (2006) History of the development of low dosage hydrate inhibitors. Energy Fuel 20:825-847
18. Movareji MK, Charffarkhah A, Sadeghi A (2016) Effect of three representative surfactants on methane hydrate formation rate and induction time. Egypt J Pet 26:231-339

19. Odutola TO, Ajienka JA, Onyekonwu MO, Ikiensikimama SS (2017) Design, fabrication and validation of a laboratory flow loop for hydrate studies. Am J Chem Eng 5(3-1):28-41. https:// doi.org/10.11648/j.ajche.s.2017050301.14

20. Oluwunmi PA, Finney AR, Rodger PM (2015) Molecular dynamics screening for new kinetic inhibitors of methane hydrate. Canad J Chem 93:1043-1049. https://doi.org/10.1139/cjc-2015-0003

21. Orlin L, Ahmed AA, Stephen O, Oliver C (2009) Successful application of an inhibitor concentration detection system in optimizing the kinetic hydrate inhibitor (KHI) injection rates and reducing the risks associated with hydrate blockage. Paper IPTC 13765 Presented at International Petroleum Conference Johari, Qatar.

22. Palermo T, et al (1997) Pilot loop tests of new additives preventing hydrate plug formation. In: Proceedings of Multiphase Conference, Cannes, France, p 133

23. Perrin A, Musa OM, Steed JW (2013) The chemistry of low dosage clathrate hydrate inhibitors. Chem Soc Rev 42(5):1996-2015. https://doi.org/10.1039/c2cs35340g

24. Peytavy J-L, Glénat P, Bourg P (2008) Qualification of low dose hydrate inhibitors (LDHIs): field cases studies demonstrate the good reproducibility of the results obtained from flow loops. In: Proceedings of the 6th International Conference on Gas Hydrates (ICGH 2008), Vancouver, British Columbia, CANADA, July 6-10.

25. Sergey S, Zachary A, Sanjeev J, Amadeu KS, Sloan ED, Koh C (2011) Measurements to characterize the pluggability of crude oils. In: Proceedings of the 7th International Conference on Gas Hydrate (ICGH). Edinburg, Scotland, United Kingdom.

26. Sloan ED, Koh CA, Sum AK, Ballard AL, Shoup GJ, McMullen N, Creek JL, Palermo T (2009) Hydrates: state of the art inside and outside flowlines. SPE Paper 118534. JPT Distinguished Lecture Series.

27. Sloan ED, Koh C (2007) Clathrate hydrate of natural gases. CRC Press, London

28. Talaghart MR (2011) Experimental investigation of induction time for binary mixtures during gas hydrate formation in the simultaneous presence of the PVP and L-Tyrosine As Kinetic Inhibitors In A Flow Mini- Loop Apparatus. J Chem Pet Eng 45(2):153-166

29. Xiao C, Adidharma H (2009) Dual function inhibitors for methane hydrate. Chem Eng Sci 64(3009):1522-1527

30. Zhang $\mathrm{P}, \mathrm{Wu} \mathrm{Q}, \mathrm{Mu} \mathrm{C}$ (2017) Influence of temperature on methane hydrate formation. Sci Rep. https://doi.org/10.1035/ 541598-017-08430-7

Publisher's Note Springer Nature remains neutral with regard to jurisdictional claims in published maps and institutional affiliations. 